\title{
ENGLISH DAY (E-DAY): GRUPO DE DISCUSSÕES NA LÍNGUA INGLESA REALIZADO PELO COMPET
}

DOI: 10.37702/2175-957X.COBENGE.2021.3395

Aline Oliveira Vaz - alineoliveiravaz@gmail.com

Centro Federal de Educação Tecnológica de Minas Gerais

Rua Pará de Minas 1026

30730-440 - Belo Horizonte - MG

Sandro Renato Dias - sandrord@cefetmg.br

Centro Federal de Educação Tecnológica de Minas Gerais

Rua Deputado André de Almeida 229

31330-530 - Belo Horizonte - MG

André Rodrigues da Cruz - andrercruz@gmail.com

Centro Federal de Educação Tecnológica de Minas Gerais

Rua Coronel Agostinho da Fonseca 333

- São Paulo - SP

Resumo: $O$ estudo da língua inglesa no grupo PET do curso de Engenharia de Computação, relaciona as expectativas do mercado de trabalho e nível de conhecimento dos integrantes. Realizado no Centro Federal de Educação Tecnológica de Minas Gerais/Campus II. O English Day (E-Day) é um encontro semanal realizado a distância na língua inglesa, em que são levantados debates acerca de um tema pré-definido, intencionando fomentar as capacidades argumentativas e de domínio do idioma estrangeiro. Para obtenção de dados foi aplicado um questionário com perguntas objetivas a fim de mensurar o desempenho dos participantes nas reuniões, ao que foi levado em consideração para a análise e discussão da atividade do grupo. Os resultados mostram que a atividade fora de valia mediana para atingir a proposta, visto que mais da metade dos participantes constataram não perceber evolução no domínio da língua. Além do formato formal da atividade ter sido levantado como ponto de reavaliação. Diante ao que foi evidenciado conclui-se que deve ser mantido o E-Day com alteração no formato para transformá-lo em uma atividade mais informal e descontraída.

Palavras-chave: Debates. Língua inglesa. Aprendizado de idiomas. Educação. 


\section{(C. COBENGE e IV Simpósio Internacional de Educação em Engenharia 2021 ie 28 a 30 de SETEMBRO

Língua estrangeira. 


\section{ENGLISH DAY (E-DAY): GRUPO DE DISCUSSÕES NA LÍNGUA INGLESA REALIZADO PELO COMPET}

\section{INTRODUÇÃO}

O mercado sofreu grandes alterações devido à globalização, as companhias passaram a ser mais exigentes no processo de contratação de novos funcionários devido a fatores como a valorização do capital intelectual e ao crescente nível de qualificação dos candidatos. Nisso, as empresas passaram a interagir de maneira global, levando a demandar profissionais com capacidades específicas, como o conhecimento de uma língua estrangeira.

A língua estrangeira mais comumente adotada nas mútuas relações foi o inglês, em virtude de sua classificação de língua internacional ou franca no mundo todo. Especialmente pelo seu número de falantes, extensão e propósito de seu uso, e em decorrência de diversos fatores políticos, culturais e tecnológicos. A imersão da língua inglesa tanto na cultura de massa quanto na pesquisa científica representa um "quase monopólio" (LE BRETON, 2005) no setor de inovação tecnológica.

Em linhas gerais, é possível inferir que o fato de o estudante brasileiro não ter habilidades com línguas estrangeiras possui diversos impactos em políticas públicas de incentivo à internacionalização da educação. A caráter de exemplificação, segundo noticiado pela Revista Veja em 2014, o extinto programa Ciência sem Fronteiras teve problemas com alunos que tiveram de retornar ao Brasil por falta de proficiência na língua inglesa. Assim, são revelados problemas estruturais no ensino da língua e ineficiência na aplicação de recursos públicos destinados à educação superior.

Nas principais universidades do país, o investimento no ensino da língua é de caráter ínfimo, ao passo que, em grande parte das universidades em países europeus ou asiáticos o cenário é oposto. Em um levantamento publicado pela empresa Education First (EF), de outubro de 2012, os brasileiros ficaram no $46^{\circ}$ lugar no Índice de Proficiência em Inglês (EPI), à frente de apenas oito países. Revelando que o nível acadêmico do país não prepara os estudantes na internacionalização do ensino superior brasileiro.

A universidade deve se preocupar com os profissionais egressos, no intuito de buscar o seu retorno à vida acadêmica, visando à atualização e à capacitação continuada dos instrumentos necessários ao exercício de sua prática profissional; deve, ainda, existir por parte das instituições empregadoras, diretrizes e metas que assegurem a continuidade dos estudos aliados à atividade docente (JESUS, 2015).

Jesus (id) ainda destaca, que: "Acima de tudo, esses profissionais devem se mostrar interessados em sua própria atualização. Sempre em busca de novas proposições que possam fortalecer a classe, para enfrentar as novas demandas da profissão, tendo em vista uma melhor preparação para o momento competitivo vivenciado no mercado de trabalho, caso contrário a qualidade de ensino no País fica comprometida.".

Sendo o inglês a principal ferramenta de comunicação utilizada para manter contato com os negócios dominantes da economia global, uma empresa que queira competir no mercado atual necessita de profissionais com conhecimento avançado neste idioma e, por isso, segundo pesquisas realizadas, cerca de $80 \%$ das empresas brasileiras 
exigem de um engenheiro recém formado o conhecimento da língua inglesa (BALESTRASSI \& MISHIMA, 2008).

O mercado de trabalho apresenta demandas específicas sobre o grau de proficiência profissional na língua inglesa e requisitos básicos em outros aspectos, como capacidade de compreensão escrita, contextualização e conhecimento técnico do idioma na área de atuação do especialista. Segundo Pinna (2001), "O inglês básico há muito deixou de ser um diferencial para ser uma exigência. Nos processos de seleção, quem não fala fluentemente nem é chamado para fazer a entrevista". No mundo da tecnologia isso é ainda mais evidente, tendo o inglês como idioma oficial da área.

Nesse ínterim, para a execução da presente série de reuniões, fez-se necessário a mútua relação entre as disciplinas do curso de Engenharia de Computação e temas culturais diversos, proporcionando a interdisciplinaridade entre línguas estrangeiras e as áreas técnicas, cotidianas e tecnológicas.

O English Day (E-Day) foi criado para que os membros do Programa de Educação Tutorial de Engenharia de Computação (COMPET) do [REVISÃO CEGA] ([REVISÃO CEGA]) se reunissem semanalmente a fim de difundir e treinar o domínio da língua inglesa. Sendo discutidos temas pré-definidos, com a intenção de aumentar a capacidade argumentativa e de domínio no idioma estrangeiro. Foram realizados os encontros em dois formatos: Apresentações em Equipes e, posteriormente, Rotação de Equipes.

Sendo assim, o E-Day foi realizado com objetivo de melhorar o conhecimento da língua inglesa e a interatividade entre os membros da equipe. Por fim, essa atividade possui como cerne a dependência do conhecimento do idioma estrangeiro para a integração ao mercado de trabalho e o enriquecimento de vocabulário, valores e visões de mundo das diferentes culturas internacionais que o entendimento de uma nova língua pode propiciar.

\section{METODOLOGIA}

Diante da tarefa de preparar e auxiliar o desenvolvimento de seus membros, o COMPET programou uma rotina de experiência semanal com o idioma estrangeiro. Neste, os membros da equipe auxiliam-se e progridem concomitantemente seus domínios da língua inglesa a modo que os estudantes com maior proficiência e habilidade nivelam, para um alto nível, seus companheiros, ao propiciar uma imersão idiomática para todos, permite-os experienciar uma oportunidade de progresso profissional e pessoal.

Sendo assim, adotou-se neste projeto a metodologia ativa de aprendizagem entre pares ou equipes (PINTO et al., 2012). Nesta, se tem o benefício de tornar mais simples a forma como os conceitos são explicados, assim como há a contribuição tanto na formação do pensamento crítico, quanto na capacidade de se respeitar opiniões divergentes.

\subsection{Apresentações em Dupla}

Em primeira análise, para a realização dos encontros de E-Day, foi proposto o voluntariado de duplas durante as reuniões semanais para a então elaboração de uma apresentação, de conteúdo e exposição totalmente em língua inglesa, por parte de participantes do grupo.

Em seguida, com tempo de preparação e execução quinzenal, por parte dos integrantes, foi necessário conexão com a internet para acesso à reunião semanal do grupo PET, além de dispositivos de entrada e saída de áudio acoplados a um computador. Dessa maneira, a critério dos apresentadores, uma plataforma de apresentações de 
slides poderia ser utilizada, para que, nas datas correspondentes, fosse feita a exposição da mesma aos demais do grupo.

\subsection{Rotação de Equipes}

Em segunda análise, foram feitas alterações na metodologia do E-day, uma vez fora apontado pelos integrantes que a duração da reunião acabava ficando muito extensa.

Nisso, fora adotado o método de rotação de equipes, findando que um grupo menor dos membros, em cada reunião, praticasse a conversação no idioma, e o restante o entendimento na escuta. O grupo na rotação foi definido como uma das equipes internas do COMPET, sendo estas: Marketing, Administração, Desenvolvimento e Eventos.

A ordem das equipes era definida previamente e as equipes seguintes eram consultadas para que pudessem se preparar para sua apresentação em inglês, garantindo que estariam aptas a falar sobre suas tarefas e responder eventuais dúvidas que os outros membros tivessem.

Em sequência, a cada reunião geral, a equipe da rotação em questão deveria realizar seu relatório semanal na língua estrangeira, enquanto os outros participantes seguiam a comunicação em português. Passado esse momento, a equipe selecionada voltaria a falar em português.

Por fim, após cada ciclo de reuniões, ao abranger as 4 equipes internas, todas eram novamente ordenadas para um novo ciclo.

\section{DISCUSSÃO E RESULTADOS}

Findando relatar e tecer os comentários sobre as análises e pareceres pela ótica dos membros, foram elaborados formulários de retorno para tomar conhecimento das dificuldades e pontos fortes dos formatos adotados pelo evento.

Assim, tendo por base esse espectro, com a captação de um retorno, buscou-se a aprimoração dos métodos e aplicá-los de forma proveitosa aos membros do grupo.

\subsection{Apresentações em Dupla}

Depois que todos os membros do COMPET apresentaram em duplas no modelo semanal, foram feitas duas avaliações.

A primeira avaliação foi executada por meio de um formulário Google, intitulado de "Avaliação E-Day - Apresentações em Dupla", a qual captava de forma anônima as respostas às perguntas levantadas. O formulário foi constituído por 5 questões, sendo 3 de escala de avaliação entre 1 e 5, com 1 indicando "Muito Insatisfeito" e 5 "Muito Satisfeito". Já as outras 2 perguntas captaram respostas de alternativas específicas.

As perguntas de escala foram:

- O quanto você gostou de participar desse modelo de E-Day?;

- Você sentiu evolução em seu inglês participando do E-Day?;

- Você acha adequado o tempo de duração do E-Day?

Já as 2 de assinalação específica foram:

- Se o participante era petiano (colaborador no grupo PET) ativo ou não;

- Você já havia feito ou assistido a alguma apresentação em inglês antes?

O formulário "Avaliação E-Day - Apresentações em Dupla" obteve as respostas dos 22 membros participantes, conforme os gráficos apresentados nas Figuras 1, 2, 3, 4 e 5. 
A partir disso, é possível inferir que, apesar do modelo ter tido boa aceitação dentre os membros, uma revisão no método seria necessária, uma vez que os índices de evolução em decorrência do evento não atingiram as expectativas. Além do tempo de duração ter sido pautado como não adequado, sugerindo uma dinâmica menos extensa.

Figura 1 - Compilação gráfica das respostas da pergunta sobre ser ou não um petiano ativo.

Você é:

23 respostas

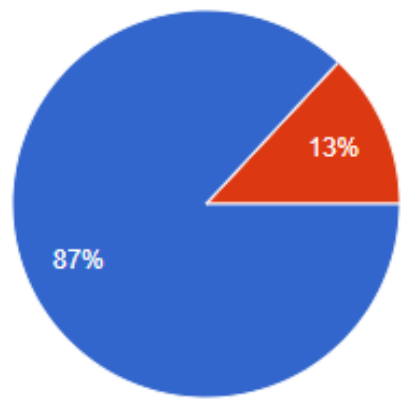

Petiano ativo

Ex petiano

Fonte: Formulário Google produzido pelo COMPET.

Figura 2 - Compilação gráfica das respostas da pergunta sobre o quanto o participante gostou do modelo do evento.

O quanto você gostou de participar desse modelo de EDay?

23 respostas

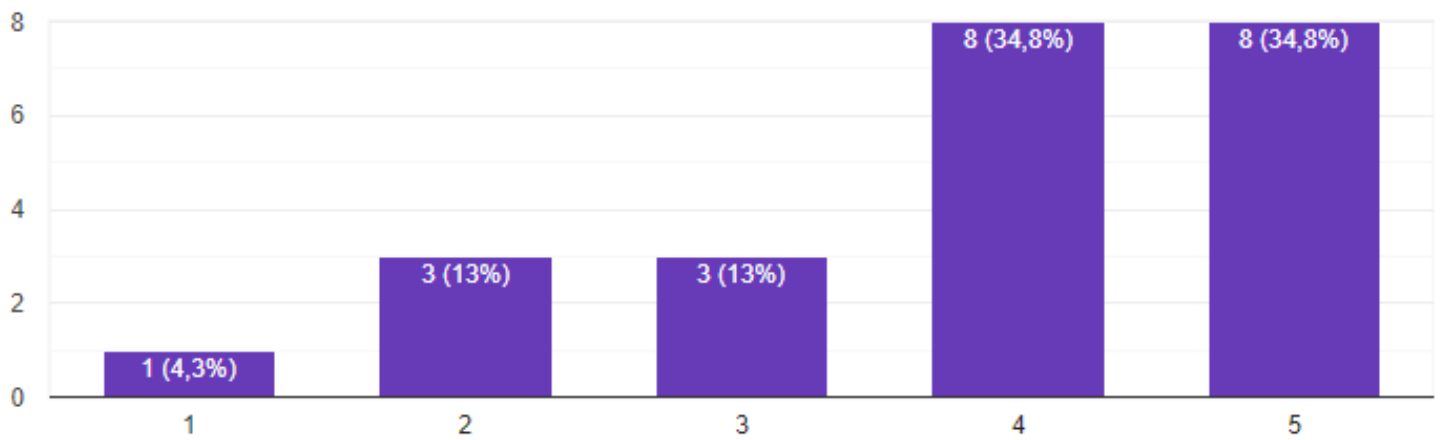

Fonte: Formulário Google produzido pelo COMPET.

Figura 3 - Compilação gráfica das respostas para a pergunta se o participante já havia participado de apresentações no modelo. 
Você já havia feito ou assistido a alguma apresentação em inglês antes?

23 respostas

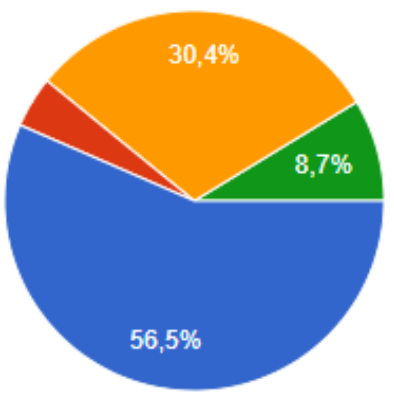
Já havia assistido
Já havia apresentado
Já havia assistido e apresentado
Nunca havia assistido nem apresentado

Fonte: Formulário Google produzido pelo COMPET.

Figura 4 - Compilação gráfica das respostas da pergunta acerca da percepção de evolução no inglês.

Você sentiu evolução em seu inglês participando do EDay?

23 respostas

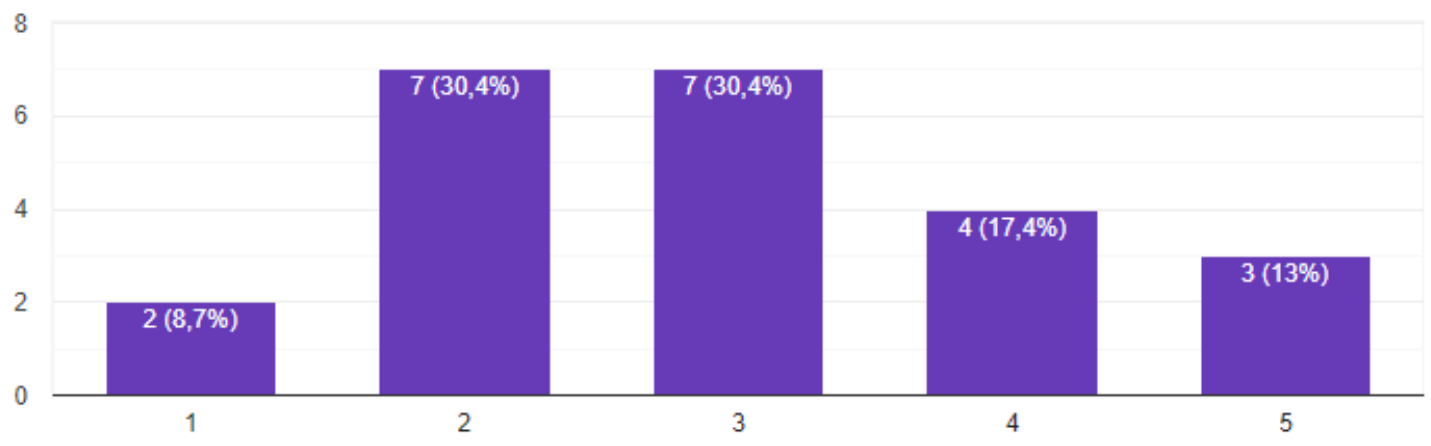

Fonte: Formulário Google produzido pelo COMPET.

Figura 5 - Compilação gráfica das respostas da pergunta sobre a opinião acerca da duração do evento.

Você acha adequado o tempo de duração do EDay?

23 respostas

8

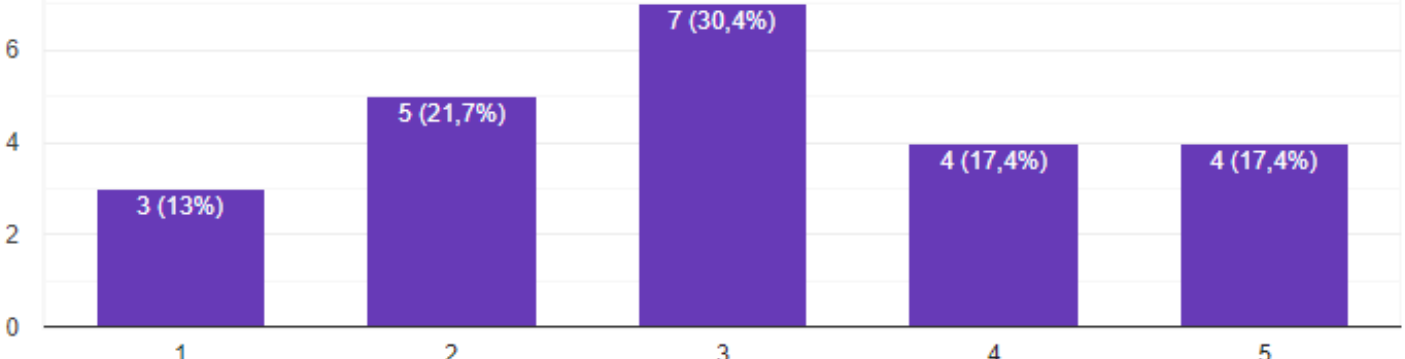


Fonte: Formulário Google produzido pelo COMPET.

A segunda avaliação foi executada pela plataforma de mensagens instantâneas Telegram no grupo do COMPET, esta, com o título de "Modelo E-Day". Assim, tendo como objetivo verificar, dentre cinco opções, se os membros concordavam em manter o modelo de apresentações em duplas, ou, caso contrário, se outro modelo organizacional seria o mais apropriado.

Dentre as opções extras haviam as sugestões de execução por apresentações, rodas de conversa, integração parcial na reunião, integração total na reunião ou gamificação (metodologia de apresentação por meio de jogos dinâmicos).

O segundo formulário "Modelo E-Day" obteve 19 integrações no total. Assim, tendo uma porcentagem de $25 \%$ para rodas de conversa, $44 \%$ integração parcial na reunião, $12 \%$ para integração total na reunião e $19 \%$ para gamificação.

A partir disso, foi possível concluir, que, em linhas gerais, o E-Day não foi respondido como absolutamente satisfatório para todos os integrantes do COMPET. Entretanto, nos quesitos de aprendizado, satisfação e método de realização, foi possível perceber uma evolução para os integrantes com menor costume e domínio do inglês (fala escrita e compreensão).

Por fim, dessa maneira, o evento fora mantido como forma de aprendizado e discutida a adaptação, posteriormente, de forma a abranger de forma satisfatória as necessidades do grupo.

\subsection{Rotação de equipes}

Após a mudança de metodologia do evento para Rotação de Equipes, fora feita a avaliação do mesmo por meio de outro formulário no Google Forms, preenchido pelos membros do COMPET e, também, ex-membros que participaram da atividade. $O$ documento foi disponibilizado durante um tempo pré-definido para ser preenchido.

O formulário foi constituído por 5 questões, sendo 2 de escala entre 1 e 5 e as outras 3 com respostas "sim" ou "não".

As perguntas de escala foram:

- O quanto você gostou de participar desse modelo de E-Day?

- Você sentiu evolução em seu inglês participando do E-Day?

Já as 3 de "sim" ou "não" foram:

- Em relação ao modelo anterior (apresentações em dupla), você acha que foi:

- Você deixou de entender algo devido ao E-Day?

- Você deixou de perguntar algo devido ao E-Day?

Ademais, ao final do espaço de entrada das respostas, o formulário possuía um espaço para sugestões e dicas para E-Day's futuros.

Ao analisar o formulário de avaliação, houveram, ao todo, 15 respostas, sendo 14 petianos ativos e 1 ex-membro, na época do preenchimento. Dentro dos tópicos avaliados, o modelo de execução da atividade (Figura 6) obteve uma nota alta. Dessa maneira, observável que 9 pessoas, o equivalente a $60 \%$ da amostra total, avaliaram com nota máxima, isto é, 5 em 5 na avaliação qualitativa, além de outros $4(26,7 \%)$ responderam com uma nota 4 em 5 .

Apesar do resultado positivo nesse quesito, consta no formulário que mais da metade dos participantes não sentiram evolução na língua inglesa com a participação no E-Day (Figura 7). Fato que pode ser justificado por um possível ruído na comunicação durante as reuniões. Como mostrado na Figura 8, 26,7\% dos participantes deixaram de 
compreender algo durante o evento, por possível improficiência dos participantes falantes e ouvintes.

Figura 6 - Compilação gráfica das respostas da

pergunta sobre o quanto o participante gostou do modelo do evento.

O quanto você gostou de participar desse modelo de EDay?

15 respostas

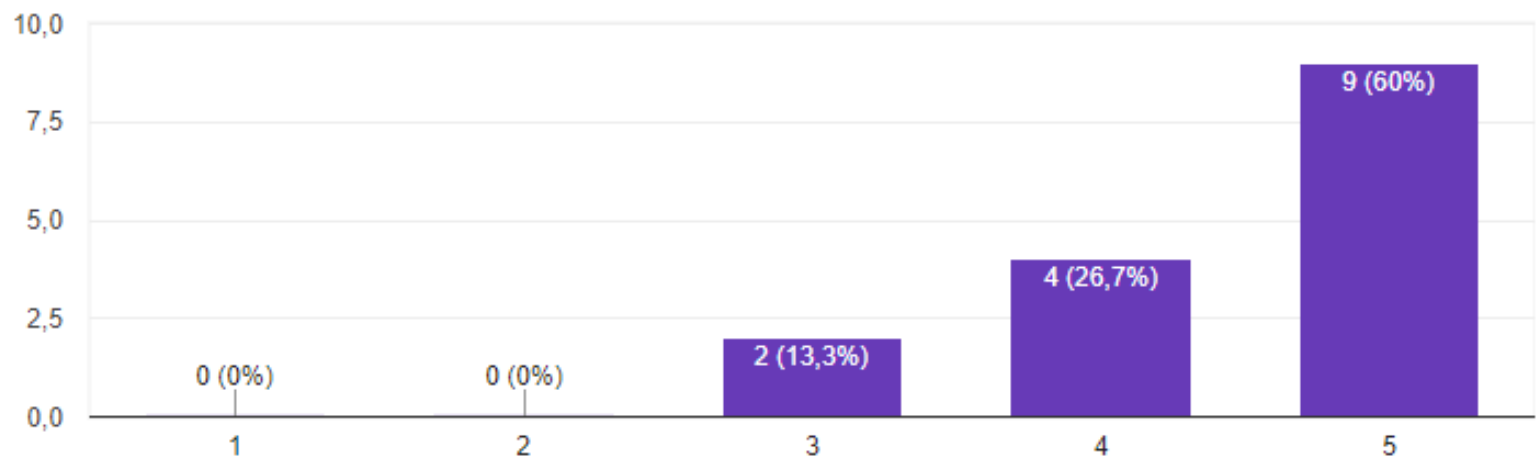

Fonte: Formulário Google produzido pelo COMPET.

Figura 7 - Compilação gráfica das respostas da pergunta acerca da percepção de evolução no inglês.

Você sentiu evolução em seu inglês participando do EDay?

15 respostas

8

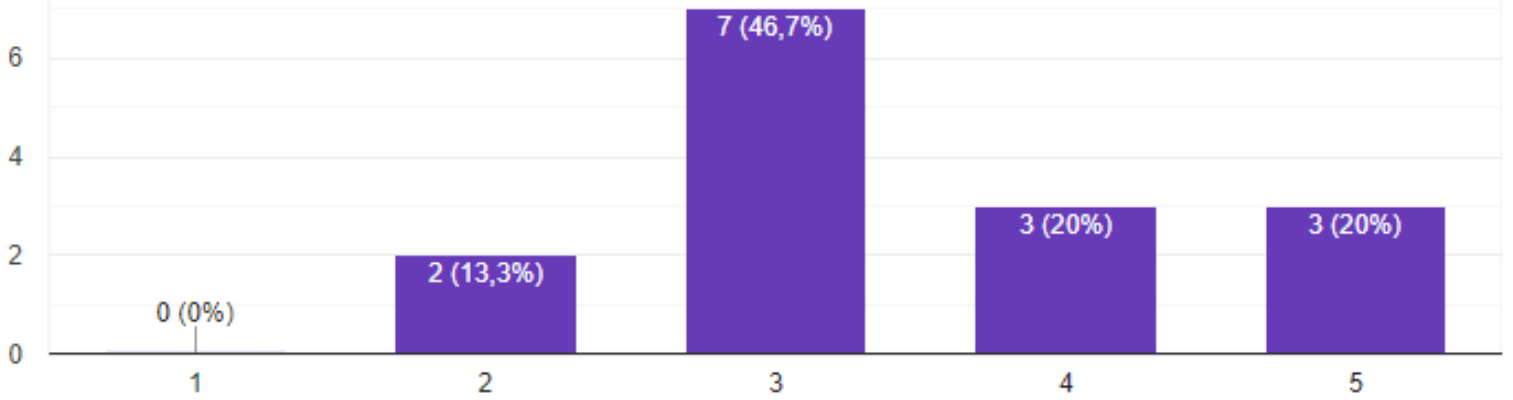

Fonte: Formulário Google produzido pelo COMPET.

Figura 8 - Compilação gráfica das respostas acerca da percepção do entendimento na língua durante os encontros. 
Você deixou de entender algo devido ao EDay?

15 respostas

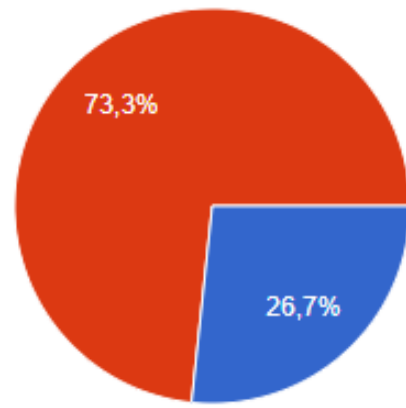

Fonte: Formulário Google produzido pelo COMPET.

Outrossim, considerando que os temas abordados nos dias do evento foram relacionados a assuntos na área de computação, o formalismo técnico da linguagem neste formato deve ser levado em consideração na avaliação do baixo rendimento dos membros.

Como sugestões ao final do formulário foram sugeridas algumas mudanças pontuais na atividade, como reconsideração do formato técnico-formal para uma conversação informal e descontraída, a fim de auxiliar que os membros estejam mais confortáveis.

\section{CONSIDERAÇÕES FINAIS}

A partir do evento, é possível levantar recortes a respeito do papel da relevância emocional, de motivação profissional, valores e metas para o aprendizado e aprimorar a técnica idiomática. Nesse sentido, destaca-se que a busca pelo conhecimento em uma língua estrangeira na vida adulta parte de uma vontade do indivíduo, podendo ser impulsionada por um ambiente de trocas valiosas de forma mais descontraída. Assim, a mitigar conflitos e frustrações no processo.

Segundo Santana (2008), fatores como ansiedade, inibição, extroversão/introversão, auto-estima, motivação, estilo de aprendizagem, aptidão para línguas e perfeccionismo podem ser pautados como tópicos passíveis a levar um bloqueio no processo de aprendizagem do indivíduo. Estes, geralmente associados a sentimentos negativos, tidos como obstáculos na aprendizagem de adultos.

Ademais, ainda é de relevante importância o aprendizado de novos idiomas, e a oportunidade de prática dentro das universidades representa avanços para a universalidade da educação brasileira e a própria aprimoração na formação do indivíduo.

O aprendizado da língua estrangeira estimula o diferente raciocínio do falante acerca da diversidade cultural dentre as particularidades de cada idioma, dessa maneira botando em prática a conceitualização e aplicação do idioma com maior relação lógica e prática.

Em suma, com o evento foi possível perceber a construção do conhecimento em inglês não apenas na semântica, mas também outros valores centrais na afetividade de ambiente para aprendizado e desenvolvimento psicológico, que podem influenciar os indivíduos na aquisição das habilidades necessárias para adquirir proficiência na linguagem. 
Por fim, é acreditado que a realização de rodas de conversação como as do evento, apesar de suas particularidades, vê-se de extrema importância na educação superior pública brasileira geral e no contexto do evento, trazendo benefícios pessoais e profissionais aos envolvidos.

\section{Agradecimentos}

Ao [REVISÃO CEGA] como instituição e à Diretoria de Graduação pela oportunidade de integração nas atividades do grupo e produção intelectual.

\section{REFERÊNCIAS}

BALESTRASSI, P. P.; MISHIMA, E. Exigências para ingressar no mercado de trabalho na condição de engenheiro recém-formado. Revista P\&D em Engenharia de Produção, No 8, 2008.

Índice de Proficiência em Inglês. EF (EF English Proficiency Index), 2012. Disponível em:https://www.ef.com/assetscdn/WIBIwq6RdJvcD9bc8RMd/legacy/ / /media/centralefc om/epi/downloads/full-reports/v2/ef-epi-2012-report-en.pdf. Acesso em: 21, abr. 2021.

GOULART, N. A manobra delicada do Ciência sem Fronteiras. Revista Veja, São Paulo, 24, fev. 2013. Disponível em: https://veja.abril.com.br/educacao/a-manobra-delicada-do-ciencia-sem-fronteiras/. Acesso em: 21, abr. 2021.

JESUS, L. C. B. O profissional da informação e a barreira linguística. Revista Brasileira de Educação em Ciência da Informação, v. 2, n. 1, 2015.

LE BRETON, J. M. Reflexões anglófilas sobre a geopolítica do inglês: In: RAJAGOPALAN, K. A geopolítica da língua inglesa e seus reflexos no Brasil. São Paulo: Parábola Editorial, 2005.

PINNA, R. Inglês não basta. Revista Tecnologia da Informação Master, 2001. Disponível em: http://www.timaster.com. br/revista/materias/main materia.asp?codigo=276. Acesso em: 17 abr. 2021.

PINTO, A. S. S.; BUENO, M. R. P.; SILVA, M. A. F. A.; SELLMANN, M. Z.; KOEHLER, S. M. F. Inovação Didática-Projeto de Reflexão e Aplicação de Metodologias Ativas de Aprendizagem no Ensino Superior: uma experiência com "peer instruction". Janus, v. 9, n. 15, 2012.

POR falta de proficiência em inglês, 110 bolsistas do Ciência sem Fronteiras vão voltar para o Brasil. Revista Veja, 9, abr. 2014. Disponível em: https://veja.abril.com.br/educacao/por-falta-de-proficiencia-em-ingles-110-bolsistas-do-cie ncia-sem-fronteiras-vao-voltar-para-o-brasil/. Acesso em: 21, abr. 2021.

SANTANA, G. M. de. A dimensão afetiva no processo de ensino-aprendizagem de línguas estrangeiras. Anuario brasileño de estudios hispánicos XVIII, 106-112, 2008. 
Abstract: The study of the english language in the Academic Group of Computer Engineering course, is related to the expectations of the job market and the level of knowledge of the members. The event held at the [BLIND REVIEW]/Campus II called English Day (E-Day) is a weekly at distance meeting in the English language, where debates are raised on a predefined theme, intending to foster the argumentative and mastery of the foreign language. To obtain data, a questionnaire with objective questions was applied in order to measure the performance of the participants in the meetings, which was taken into consideration for the analysis and discussion of the group's activity. The results show that the activity was not of average value to reach the proposal, since more than half of the participants found that they did not perceive progress in the language domain. In addition to the formal format of the activity being raised as a point of reevaluation. In light of what has been evidenced, it is concluded that the E-Day should be maintained with a change in format in order to transform it into a more informal and relaxed activity.

Keywords: Debates. English. Language learning. Education. Foreign language. 